\title{
Retinal artery occlusion as a probable idiosyncratic reaction to topical minoxidil: a case report
}

\author{
Ramesh Venkatesh ${ }^{*}$ D, Arpitha Pereira, Nikitha Gurram Reddy and Naresh Kumar Yadav
}

\begin{abstract}
Background: Minoxidil hair formulation is commonly used for the treatment of male or female androgenic alopecia. This over-the-counter product is considered safe, but should be used with caution. Ocular side effects following topical minoxidil use are rarely reported. In this paper, we report a rare case of inferior hemiretinal artery occlusion possibly caused by topical 5\% minoxidil treatment.

Case description: A 21-year-old Asian Indian male presented to the retina clinic with sudden onset blurring of vision and superior visual field loss in the right eye since morning. He was diagnosed with androgenic alopecia and was on treatment with topical 5\% minoxidil spray twice a day for the last 3 years. On examination, his corrected distance visual acuity was 6/6, N6 in both eyes. Anterior segment examination and intraocular pressure in both eyes and left eye fundus were within normal limits. Right eye fundus examination showed features suggestive of inferior hemiretinal artery occlusion, which were confirmed on fluorescein angiography and optical coherence tomography. A detailed systemic evaluation and investigations (blood pressure, random blood sugar, hematological and coagulation profile, serum homocysteine level, Mantoux test, chest x-ray, cardiac two-dimensional echography, thyroid function test, and immunological profile) did not detect any abnormalities. The ocular condition and its visual prognosis were explained to the patient, and he was asked to review after 4 weeks.
\end{abstract}

Conclusion: Though there is no definite cause-outcome relationship between topical minoxidil use and retinal artery occlusion development, this possibility should be kept in mind when observing retinal vascular occlusion cases with concurrent use of topical minoxidil.

Keywords: Minoxidil solution, Ocular, Retinal artery occlusion, Side effects

\section{Background}

Minoxidil hair formulation is commonly used in the treatment of male or female androgenic alopecia. This drug is available in the market as a $2 \%$ and $5 \%$ topical solution [1]. Minoxidil is believed to stimulate hair growth by increasing the anagen phase of the hair cycle, but the exact mechanisms remain elusive [2]. This

*Correspondence: vramesh80@yahoo.com

Dept. of Retina-Vitreous, Narayana Nethralaya, 121/C, Chord Road, 1st'R'

Block, Rajaji Nagar, Bangalore 560010, India over-the-counter product is considered usually safe, but should be used with caution.

Furthermore, minoxidil is an orally active vasodilator for treatment of severe hypertension. Typical systemic side effects of minoxidil are increased heart rate, augmented heart function and stroke volume, sodium and water retention, and abnormal hair growth [3]. The most common adverse reactions of topical formulations are limited to irritant and allergic contact dermatitis on the scalp [4]. Ocular side effects following topical minoxidil usage have rarely been reported [5-7]. The side effects following minoxidil therapy are dependent on the contact original author(s) and the source, provide a link to the Creative Commons licence, and indicate if changes were made. The images or other third party material in this article are included in the article's Creative Commons licence, unless indicated otherwise in a credit line to the material. If material is not included in the article's Creative Commons licence and your intended use is not permitted by statutory regulation or exceeds the permitted use, you will need to obtain permission directly from the copyright holder. To view a copy of this licence, visit http://creativecommons.org/licenses/by/4.0/. The Creative Commons Public Domain Dedication waiver (http://creativecommons.org/publicdomain/zero/1.0/) applies to the data made available in this article, unless otherwise stated in a credit line to the data. 
time of applied dose, concentration, and percutaneous absorption of the topical solution [8]. Herein, we report a case of inferior hemicentral retinal artery occlusion most likely caused by topical $5 \%$ minoxidil treatment.

\section{Case presentation}

A 21-year-old Asian Indian male, non-smoker, presented to the retina clinic with sudden onset blurring of vision and superior visual field loss in the right eye since waking up that morning. The patient did not give history of similar episodes in the past. He had no other significant medical history other than alopecia. Family history was not significant for similar ocular or hair problems. He was treated for androgenic alopecia with topical 5\% minoxidil spray (Am-Exidil 5 topical solution) twice a day for the last 3 years. Every application involved two puffs of spray directly applied to $40-45 \%$ of the scalp surface area. Examination of the scalp showed no signs of irritation, inflammation, or dermatitis at the time of initial presentation. On examination, his corrected distance visual acuity was 6/6, N6 in both eyes. Anterior segment examination and intraocular pressure in both eyes were within normal limits. The right eye fundus showed retinal opacification originating from the disc and spreading along the inferior arcade and involving the inferior macula with a normal foveal reflex. The left eye fundus was normal. A clinical diagnosis of inferior hemicentral retinal artery occlusion was made in the right eye. Humphrey 30-2 visual field testing showed a superior field defect (Fig. 1). Optical coherence tomography (SD-OCT, Spectralis HRA, Heidelberg Engineering, Heidelberg, Germany) of the right eye showed thickening and increased hyperreflectivity of inner retinal layers with hyporeflective outer retinal layers due to shadowing at the inferior macula (Fig. 2A). Fundus fluorescein angiography of the right eye (Spectralis HRA, Heidelberg Engineering, Heidelberg, Germany) revealed delayed filling of the inferior branch of the central retinal artery with corresponding blocked choroidal fluorescence due to retinal opacification (Fig. 2B, C). A detailed systemic evaluation and investigations (blood pressure, random blood sugar, hematological and coagulation profile, serum homocysteine level, Mantoux test, chest $\mathrm{x}$-ray, thyroid function test, and immunological profile) did not detect any abnormalities. The values of the hematological and coagulation profile were as follows: red blood cell count $5.73 \mathrm{million} / \mathrm{mm}^{3}$, packed cell volume level $46.2 \%$, mean corpuscular volume $80.6 \mathrm{fl}$, mean corpuscular hemoglobin $28.4 \mathrm{pg}$, mean corpuscular hemoglobin concentration $35.3 \mathrm{~g} / \mathrm{dL}$, red blood cell distribution width $12 \%$, platelet count 2.00 lakhs/ $\mathrm{mm}^{3}$, bleeding time 2 minutes 30 seconds, clotting time 5 minutes 30 seconds, and serum homocysteine level $8.65 \mu \mathrm{mol} / \mathrm{L}$. Cardiac evaluation with two-dimensional
(2D) echography was also found to be normal. No treatment was provided to the patient. The condition of the eye and its visual prognosis was explained to the patient, and he was asked to review after 1 week. After 1 week, his visual acuity was $6 / 6$, N6 in both eyes. There was reduction in the retinal opacification. At 4 weeks, there was complete resolution of the inferior retinal opacification and thinning and atrophy of the inner retinal layers while the complaint of superior field defect still remained (Fig. 3). Written informed consent was obtained from the patient for including his clinical data and images in this report.

\section{Discussion and conclusion}

A retinal artery occlusion occurs when the central retinal artery or one of its branches gets occluded leading to retinal opacification in the affected segment and visual field loss. Minoxidil sulfate is an active sulfated metabolite of minoxidil that causes opening of the K-ATP channels and vascular smooth muscle relaxation. In addition, minoxidil promotes the production of growth factors such as vascular endothelial growth factor (VEGF), and these might promote hair growth [2, 9-11]. Involvement of minoxidil in angiogenesis causes retinal capillary rearrangement and increased chances of vessel thrombosis and occlusion, which could have been the likely pathogenetic mechanism in this case [5]. Aktas et al. published a report of non-arteritic anterior ischemic optic neuropathy following short posterior ciliary artery occlusion due to high-dose and prolonged topical minoxidil usage in a young, otherwise healthy man [6]. Another non-peer-reviewed report showed retinal artery occlusion following minoxidil usage documented by a French physician in a 46-year-old lady being treated for alopecia [12]. Although retinal artery occlusion is thought to be associated with several other etiological factors such as diabetes, hypertension, coagulopathies, hyperlipidemia, and atherosclerosis, there was no known predisposing factor that could have caused a retinal artery occlusion in our patient, except for the high amount and long duration of use of topical minoxidil. The occurrence of retinal artery occlusion in an otherwise young healthy male suggests minoxidil could be the causative factor. On the basis of clinical history and ocular findings, Naranjo adverse drug reaction probability score was 5 [13], thus suggesting a probable idiosyncratic drug reaction to topical minoxidil usage. It is not possible to infer a direct relationship between topical minoxidil use and retinal artery occlusion development without prospective or retrospective studies. Thus, despite the use of minoxidil by the patient and the other online case report, the relationship between minoxidil and retinal artery occlusion 


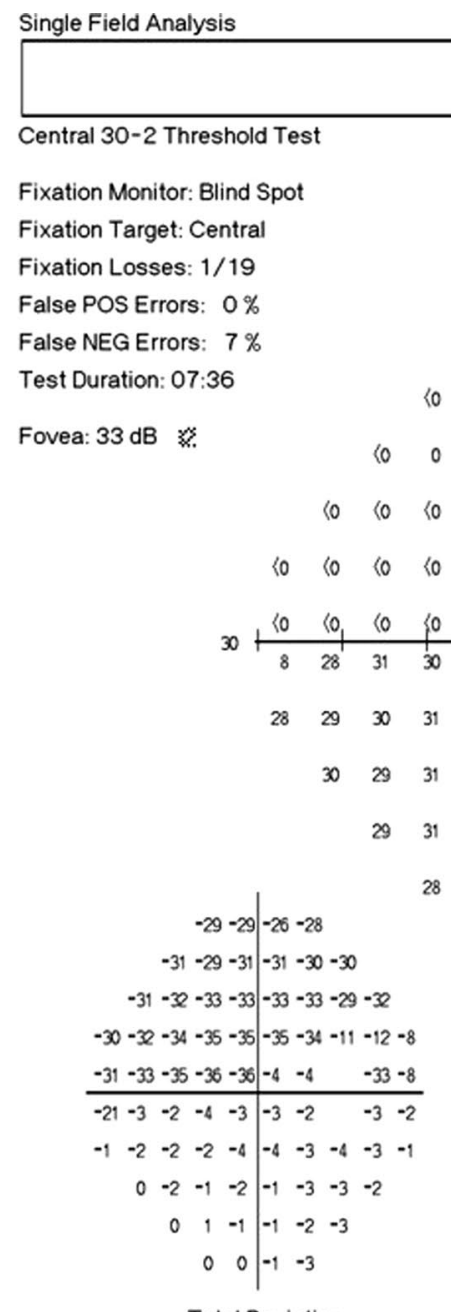

Total Deviation

口曰

口曰ם00

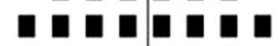

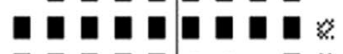

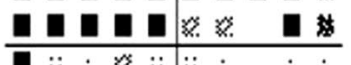

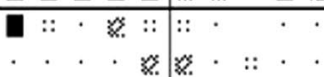

. . . . : : .

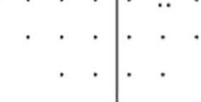

Eye: Right

DOB: 07-01-1989
Stimulus: III, White

Background: 31.5 ASB

Strategy: SITA-Standard
Pupil Diameter: $6.0 \mathrm{~mm}$

Visual Acuity: $6 / 6$

RX: DS $-1.00 \mathrm{DC} \times 180$
Date: 10-02-2020

Time: 10:35 AM
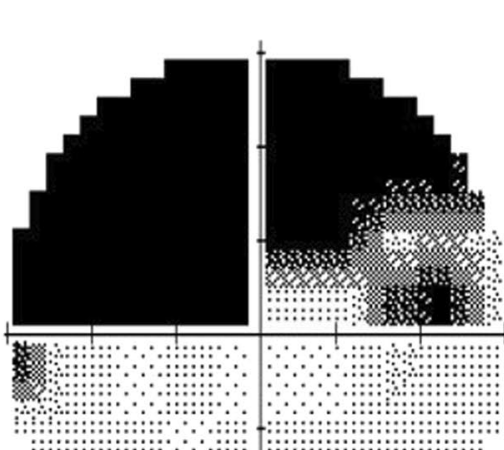

$\begin{array}{llll}30 & 28 & 29 & 30\end{array}$

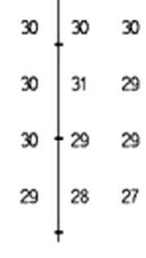

$29 \quad 29$

28

27<smiles>C1CCCCC1</smiles>

$-27-27 \mid-25-27$

$-29-27-29-29-29-29$

$-30-31-31-32-31-31-28-30$

$-29-31-32-33-33-33-33-9-10-6$

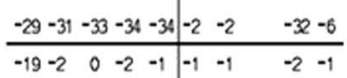

GHT

Outside Normal Limits

\begin{tabular}{lllll|lllll}
1 & 0 & 0 & 0 & -2 & -2 & -1 & -2 & -1 & 1
\end{tabular}

\begin{tabular}{llll|llll}
2 & 0 & 1 & 0 & 1 & -1 & -1 & -1
\end{tabular}

\begin{tabular}{lll|lll}
1 & 2 & 1 & 0 & 0 & -1
\end{tabular}

\begin{tabular}{ll|ll}
1 & 1 & 0 & -2
\end{tabular}

VFI $60 \%$

MD $\quad-13.83 d B P<0.5 \%$

PSD $\quad 17.33 \mathrm{~dB} P<0.5 \%$

Pattern Deviation

-10

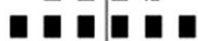

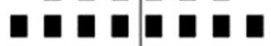

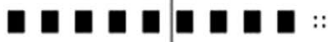

뭄.

$::<5 \%$

\% $<2 \%$

$<1 \%$

- $<0.5 \%$

Fig. 1 Humphrey visual field analysis of the right eye using the 30-2 protocol showing a superior visual field defect 


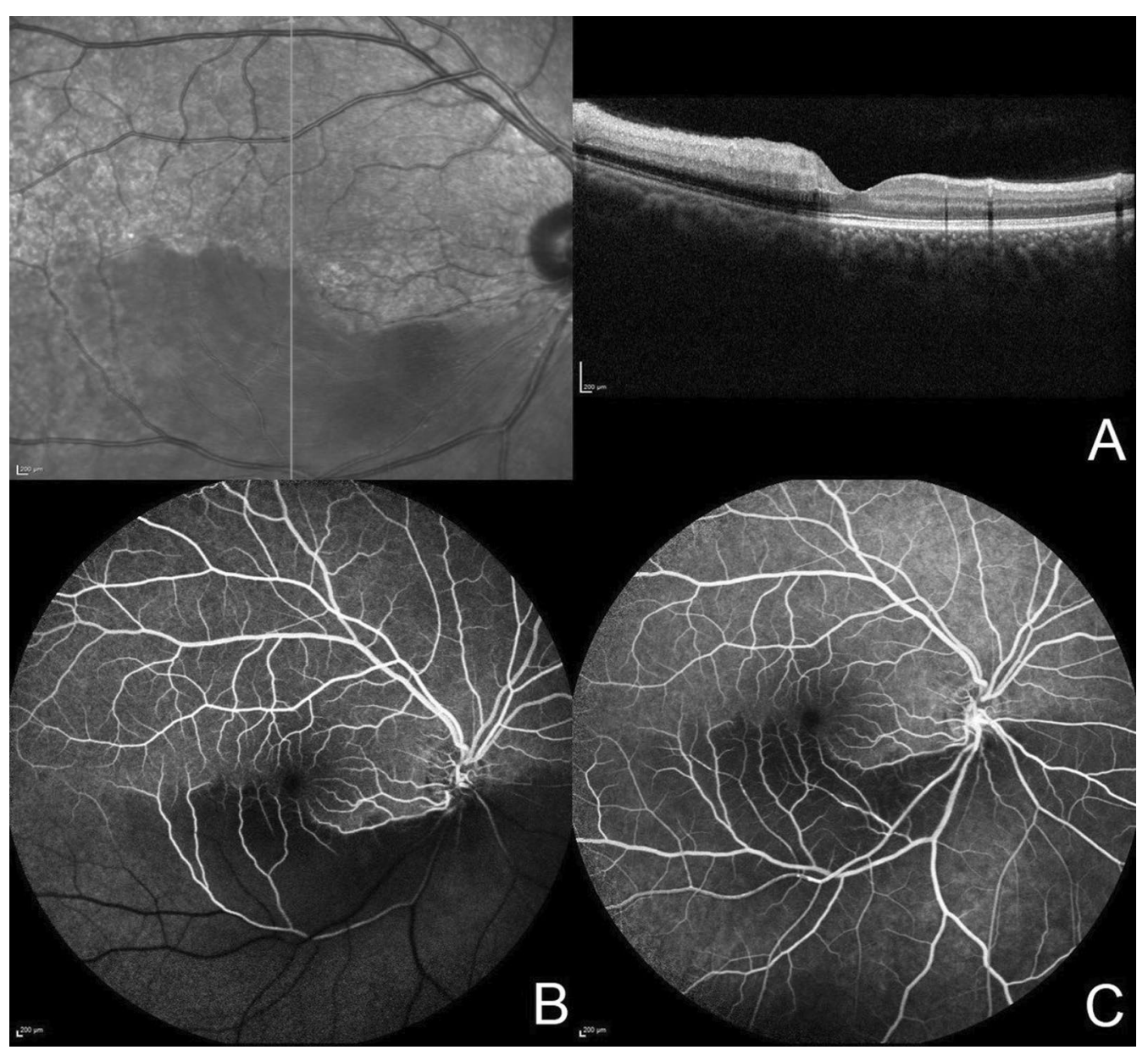

Fig. 2 Fluorescein angiography and optical coherence tomography images in a case of inferior hemiretinal artery occlusion. A Spectral domain optical coherence tomography showing thickening and increased hyperreflectivity of inner retinal layers with hyporeflective outer retinal layers at the inferior macula. B, C Fundus fluorescein angiography of the right eye showing delayed filling of the inferior branch of the central retinal artery with corresponding blocked choroidal fluorescence due to retinal opacification

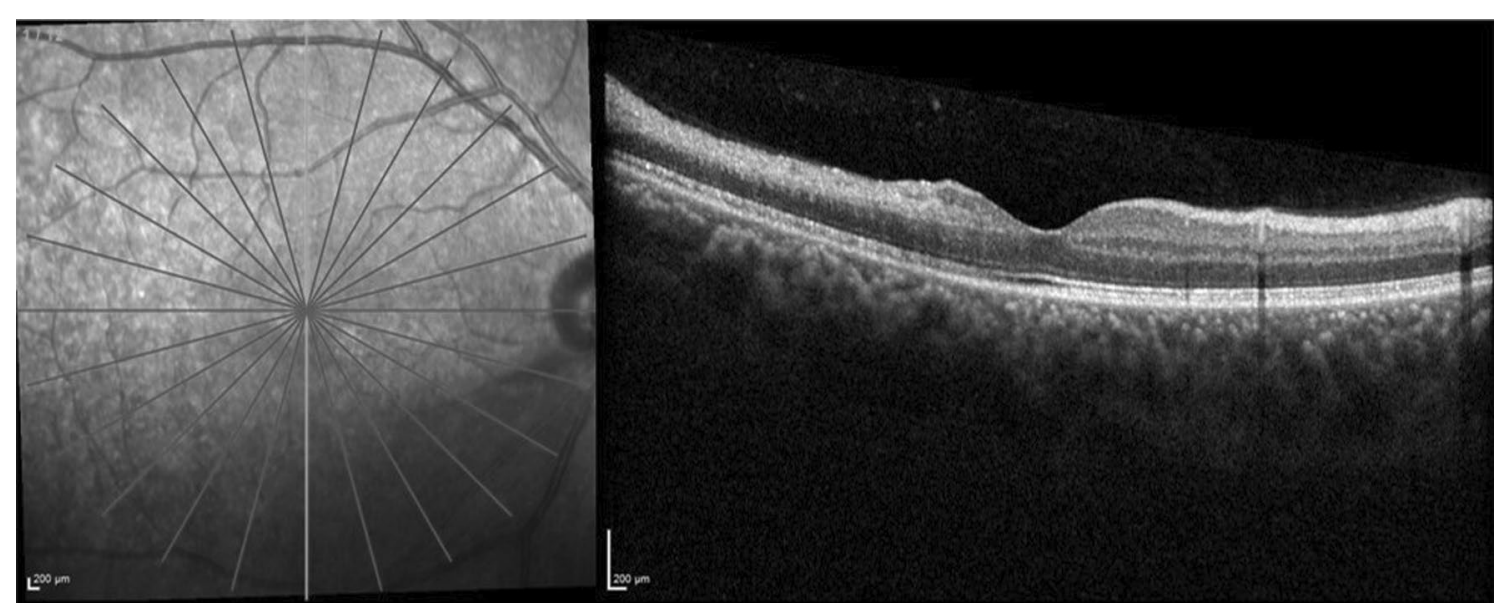

Fig. 3 Optical coherence tomography (OCT) image in a case of inferior hemiretinal artery occlusion at 4 weeks post-presentation. Vertical line scan OCT image of the right eye at 4 weeks post-presentation in a case of inferior hemiretinal artery occlusion shows thinning and atrophy of the inner retinal layers inferior to the macula. The inner retinal layers superior to the macula show normal inner retinal thickness and retinal layer stratification 
still remains unproven. It is possible that this is only by chance.

To conclude, even though there is no definite causeoutcome relationship between topical minoxidil use and retinal artery occlusion development, this potential possibility should be kept in mind when observing retinal vascular occlusion cases with concurrent use of topical minoxidil. A larger collection of cases would be required to establish a cause-outcome relationship.

\section{Abbreviations}

OCT: Optical coherence tomography; VEGF: Vascular endothelial growth factor.

\section{Acknowledgements}

We would like to thank our technician Mr. Abhishek Bhatt for his contribution in acquiring the images and providing them to us for analysis in this study.

\section{Authors' contributions}

$\mathrm{RV}$ - conceptualizing the study, analyzing the data, interpreting the findings, writing and reviewing the manuscript. NKY — reviewing the manuscript. NRdata acquisition. AP_-data analysis, interpreting the results, and reviewing the manuscript. All authors read and approved the final manuscript.

\section{Funding}

None.

\section{Availability of data and materials}

The datasets used and/or analyzed during the current study are available from the corresponding author on reasonable request.

\section{Declarations}

\section{Ethics approval and consent to participate}

All procedures performed in studies involving human participants were in accordance with the ethical standards of the institutional research committee (Narayana Nethralaya institutional review board-C-2020-05-006) and with the 1964 Helsinki Declaration and its later amendments or comparable ethical standards. The patient has provided his consent to be a part of the publication and also to use the images for publication purposes.

\section{Statement on human and animal rights}

This article does not contain any studies with animals performed by any of the authors.

\section{Consent for publication}

Written informed consent was obtained from the patient for publication of this case report and any accompanying images. A copy of the written consent is available for review by the Editor-in-Chief of this journal.

\section{Competing interests}

The authors declare that they have no conflict of interest.

Received: 29 July 2020 Accepted: 16 September 2021

Published online: 08 October 2021

\section{References}

1. Linas SL, Nies AS. Minoxidil. Ann Intern Med. 1981;94(1):61-5.

2. Messenger AG, Rundegren J. Minoxidil: mechanisms of action on hair growth. Br J Dermatol. 2004;150(2):186-94.

3. Leenen FH, Smith DL, Unger WP. Topical minoxidil: cardiac effects in bald man. Br J Clin Pharmacol. 1988;26(4):481-5.

4. Rossi A, Cantisani C, Melis L, lorio A, Scali E, Calvieri S. Minoxidil use in dermatology, side effects and recent patents. Recent Pat Inflamm Allergy Drug Discov. 2012;6(2):130-6.

5. Rastmanesh R. Alopecia and ocular alterations: a role for Minoxidil? J Recept Signal Transduct Res. 2010;30(3):189-92.

6. Aktas H, Alan S, Türkoglu EB, Sevik Ö. Could topical minoxidil cause non-arteritic anterior ischemic optic neuropathy? I Clin Diagn Res. 2016;10(8):WD01-2.

7. Venkatesh R, Pereira A, Jain K, Yadav NK. Minoxidil induced central serous chorioretinopathy treated with oral eplerenone-a case report. BMC Ophthalmol. 2020;20(1):219.

8. Ferry JJ, Shepard JH, Szpunar GJ. Relationship between contact time of applied dose and percutaneous absorption of minoxidil from a topical solution. J Pharm Sci. 1990;79(6):483-6.

9. Yum S, Jeong S, Kim D, Lee S, Kim W, Yoo J-W, et al. Minoxidil induction of VEGF is mediated by inhibition of HIF-prolyl hydroxylase. Int J Mol Sci. 2017:19(1):53.

10. Lachgar S, Charvéron M, Bouhaddioui N, Neveux Y, Gall Y, Bonafé JL. Inhibitory effects of bFGF, VEGF and minoxidil on collagen synthesis by cultured hair dermal papilla cells. Arch Dermatol Res. 1996;288(8):469-73.

11. Buhl $A E$, Waldon DJ, Baker CA, Johnson GA. Minoxidil sulfate is the active metabolite that stimulates hair follicles. I Invest Dermatol. 1990;95(5):553-7.

12. http://patientsville.com/minoxidi//retinal-artery-occlusion.htm. Accessed 23 Feb 2020.

13. Adverse drug reaction probability scale (Naranjo) in drug induced liver injury. In: LiverTox: clinical and research information on drug-induced liver injury. Bethesda (MD): National Institute of Diabetes and Digestive and Kidney Diseases; 2012. http://www.ncbi.nlm.nih.gov/books/NBK54 8069/. Accessed 15 July 2021.

\section{Publisher's Note}

Springer Nature remains neutral with regard to jurisdictional claims in published maps and institutional affiliations.

Ready to submit your research? Choose BMC and benefit from:

- fast, convenient online submission

- thorough peer review by experienced researchers in your field

- rapid publication on acceptance

- support for research data, including large and complex data types

- gold Open Access which fosters wider collaboration and increased citations

- maximum visibility for your research: over $100 \mathrm{M}$ website views per year

At BMC, research is always in progress.

Learn more biomedcentral.com/submissions 